\title{
The Occurrence of Work-related Fatigue and Job Satisfaction in Nursing Staff to the Quality of Care : A Cross-sectional Survey in North-East China
}

\section{XueJing Bi}

Harbin Medical University https://orcid.org/0000-0003-0283-0190

Qiao Zhang

Harbin Medical University

Jin-yu Niu

Harbin Medical University

Chao-yi Chen

Harbin Medical University

Ze Liu

Harbin Medical University

Liang-wen Ning

Harbin Medical University

Ning Ning

Harbin Medical University

Qun-hong Wu

Harbin Medical University

Yanhua Hao ( $\nabla$ hyhyjw@126.com )

Harbin Medical University https://orcid.org/0000-0002-0841-2291

Li-bo Liang

Harbin Medical University

"Tai" Wang Yong

RIT: Rochester Institute of Technology

\section{Research}

Keywords: work-related fatigue, job satisfaction, quality of care, nursing, mediation analysis

Posted Date: August 30th, 2021

DOI: https://doi.org/10.21203/rs.3.rs-844733/v1 
License: (c) (i) This work is licensed under a Creative Commons Attribution 4.0 International License. Read Full License 


\section{Abstract}

\section{Background}

Poor quality of care would significantly increase adverse patient outcomes. Improving the quality of care is an urgent priority. The relationship between work-related fatigue and quality of care has not been systematically explored. This paper explores the occurrence of work-related fatigue, job satisfaction, and its relationship with quality of care.

\section{Methods}

Self-report questionnaires assessing work-related fatigue and job satisfaction were distributed among 1,299 nurses from 20 hospitals in North-Eastern China. Regression analysis was performed to assess the associations between work-related fatigue, job satisfaction, and quality of care. Mediate effect analysis was used to explore the mediating role of job satisfaction.

\section{Results}

Approximately $55 \%$ of nurses got moderate or severe work-related fatigue. The results from the t-test indicated that nurses with a high level of work-related fatigue were more prone to nursing errors. The mediation analysis showed that work-related fatigue indirectly affected the quality of care through job satisfaction (indirect effect: $\beta 0.047,95 \% \mathrm{Cl} 0.040-0-054$ ), while the direct effect was $\beta 0.059,95 \% \mathrm{Cl}$ 0.050-0.068.

\section{Conclusions}

The present study concluded that more than half of the nurses surveyed were moderate to severe workrelated fatigue. Nurses with a high level of work-related fatigue were likely to provide significantly more nursing errors. We confirmed that job satisfaction was a mediator for the relationship between workrelated fatigue and quality of care. Therefore, hospitals managers and relevant management departments should consider work-related fatigue and job satisfaction among nurses to improve health services in the future.

\section{Introduction}

In a healthcare system, improving the quality of care is an urgent priority, and nurses play a vital role in influencing the quality of health services [1]. Nurse-perceived quality of care was defined as "nurses' view of the degree of excellence on the standard nursing services they provided, expectations to meet patients' satisfaction and needs" [2]. Poor quality of care would significantly increase adverse patient outcomes, such as patient injury, medication error and failure to rescue, and even high mortality [3]. According to the World Health Organization and nursing organizations, the relationship between nurses' work-related fatigue and quality of care is a significant issue in the healthcare field [4-6]. 
During the past ten years, a series of studies indicated that quality of care was related to nurses' workrelated fatigue [7]. Work-related fatigue is a common complaint encountered at the workplace [8, 9]. The elements affecting work-related fatigue are: long work hours, extended-duration work shifts, duration and intensity of work, sleep deprivation, adverse environmental conditions (noise, light), the type of work performed (psychological or physical burden), the lack of breaks for relaxing and excessive stress [8-10]. Work shifts, specifically night shifts and extended work shifts without sufficient inter-shift recovery, were linked to higher fatigue levels. Nurses' high level of work-related fatigue may not only lead to their health deterioration, disease occurrence and may also provoke severe consequences for patients [4]. Workrelated fatigue has become a significant risk for nurses working in hospitals. It has consequently led to poor outcomes such as reduced mental acuity, degradation in performance, and errors (Canadian Centre for Occupational Health and Safety, 2017). Excessive and prolonged stress from work will lead to workrelated fatigue-related declining quality of care $[7,11]$. When each nurse undertakes a large number of non-nursing tasks, it may be concluded over workload, so nurses may not be able to properly carry out tasks that require professional skills, such as training. In other words, when the number of non-nursing tasks increases, adverse patient events may occur because nurses do not have time to provide necessary supervision for patients. When the hospital lacks adequate nursing staff, patients may not receive timely care, and adverse patient events such as medication errors, patient falls, bedsores, failure of cardiopulmonary resuscitation, and death may occur $[12,13]$. For instance, fatigue nurses were more likely to make a mistake in clinical judgment that would adversely affect the quality of care [14]. A study in Taiwan testing the relationship between nursing workloads and patients' safety has revealed an association between overtime hours and patient safety indices [15]. Therefore, the relationship between quality of care and work-related fatigue is worth researchers' attention for sure.

Work-related fatigue has become a significant occupational health issue, particularly in East Asia [1618]. The unprecedented growth of the Chinese economy in past years has been accompanied by a crazy increase in the hospital demand for medical care, especially the need for hospital service [9]. Hospital service is determined by the need for psychological work, not just quantitative physical workloads. Chinese nurses are responsible for substantial work reports. Chinese nurses increased from 1.35 million in 2005 to 4.2 million in 2019 [16, 19]. However, more than $40 \%$ of outpatient visits in China occur in hospitals. Nurses still faced heavy workloads because of severe nurse shortages, characterized by long working hours, intensive repetitive work, high stress, etc. [20-22]. Although work-related fatigue of nurses and quality of care was acknowledged as critical factors in healthcare delivery, the research on the determinants of nurses' work-related fatigue and quality of care in China has not been well documented $[2,23]$.

Up to now, although the relationships between work-related fatigue and QOC have been reported previously [6], the effect of job satisfaction between work-related fatigue and QOC for nurses has not been well documented. Nurse Work Environment, Nurse Staffing, and Outcome Model (NWE-NS-OM) is used internationally to guide the study of medical outcomes [24]. It revealed that the work environment among nurses is related to work-related fatigue, severely impacted job satisfaction, burnout, and quality of care $[25,26]$. Nurses' job satisfaction is defined as: "Nurses' responses to working conditions support 
their desired needs as a result of their assessment of the value or fairness of their work experience" [27]. Previous studies indicated that high satisfaction leads to better performance and increases service quality [28]. Additionally, the causes of nurses' dissatisfaction are correlated to work-related fatigue, which is related to the work environment [29], transformational leadership, and nurse staffing [25]. Therefore, testing the role of job satisfaction as a mediator might provide insights into the direction and strength of the relationship between work-related fatigue (independent variable) and quality of care (outcome variable).

Based on previous findings, the purposes of the study are 1) work-related fatigue has a negative effect on QOC; 2) job satisfaction mediates the relationship between work-related fatigue and QOC.

\section{Methods}

\section{Ethics statement}

The Medical Ethics Committee of Harbin Medical University approved the study. The institutional review committees approved the present study. IRB code is HMUIRB20200004. Before completing the survey, all participants are willing to participate in the survey received written informed consent.

\section{Study design and participants}

A cross-sectional study was conducted from July and December of 2017. Overall, we adopt random cluster sampling. All participants were from hospitals in Heilongjiang Province, China. Nurses from 20 hospitals in six cities across this province were invited to participate in the present study. Full-time nurses employed by these hospitals from all of the units were invited to complete the questionnaire anonymously. Participants were asked to provide subjective responses to self-administered questionnaires at their workplaces. The purpose of the present research was briefly explained to participants, and they were informed that participation was voluntary. Participants were assured that all information obtained would remain confidential. Return of the completed questionnaire was deemed informed consent.

A team comprising several trained research students led by one of the principal investigators visited the participating hospitals, approached the nurses on the day of their visits, invited them to complete the questionnaire independently, and then collected. Of the 1,500 questionnaires distributed, 1,299 (86.6\%) valid questionnaires were finally included in the analysis.

\section{Measures}

\section{Demographic}

The questionnaire included questions on the following demographic characteristics: gender, age, marital status (unmarried, married/living together, other), departments, and educational level. The demographic 
data also included length of sleep ( $<6$ hours, $6-8$ hours or $>8$ hours), length of work per day ( $\leq 8$ hours or $>8$ hours) and, weekly exercise (Yes or No).

\section{Measurement of Quality of Care}

Quality of care, the dependent variable, was examined using two ways. The first section was errors that occurred during the past year, "Have you had any nursing accidents or errors in the last 12 months?"

The second section was a questionnaire based on a scale used to measure the quality of care [30]. According to different cultures, the questionnaire included five questions: decreased efficiency, poor attitude, reduced patience, reduced communication time, and increased error rate. Participants were asked to rate their response to the statement "Due to heavy workload, my work efficiency decreased" on a five-point Likert Scale ranging from 1 (strongly disagree) to 5 (strongly agree). The final score was obtained by adding all the items scored. Cronbach's alpha coefficient for the scale was 0.876 .

\section{Measurement of Job satisfaction}

Job satisfaction of participants, the variable in this study, was measured based on a response to the item, "Generally speaking, I am not satisfied with the current working situation" on a five-point Likert Scale from 1 (never) to 5 (always).

\section{Measurement of Work-related fatigue}

Work-related fatigue of nurses, the independent variable, was evaluated with the Work-Related Fatigue Scale (WRFS), a 30-item instrument with the following five dimensions: duration of working hours (L1 L4), work-related stress (R5 R10), general feeling of fatigue (G11 G20), physical fatigue accumulation (P21 P25), mental fatigue accumulation (M26 M30) [31]. Some of the items are from "Self-diagnosis Checklist for Assessment of Workers' Accumulated Fatigue" which was published by the Ministry of Health, Labor and Welfare of Japan, which has been validated in a range of healthcare Settings in Japan [32]. Each item could be rated on a five-point Likert Scale, with 0 (never) being the lowest and 4(always) the highest. The final score of each indicator was obtained by dividing the sum of all the item scores by the total number of items. The correlation coefficients between each dimension ranged from 0.668 to 0.867 , significantly positively correlated $(p<0.01)$. The Cronbach's alpha coefficient for the scale was 0.827. The total score ranged from 0 to 120 , with 0 representing the lowest degree of work-related fatigue and 120 representing the highest. Work-related fatigue was categorized as follows: I, 0-30, none; II, 3160, mild work-related fatigue; III, 61-90, moderate work-related fatigue; IV, 91-120, severe work-related fatigue.

All scores were within a reasonable range, and validity was examined. Analysis of Moment Structure (AMOS) 24 maximum likelihood estimation was used for confirmatory factor analysis to establish the scale's validity. The following conventional cut-offs were used in this present study: minimum discrepancy divided by degrees of freedom (CMIN/DF) of 3.414, an incremental fit index (IFI) of 0.949, a goodness-of-fit index (GFI) of 0.909 , a confirmatory fit index (CFI) of 0.949 , and a root mean square error of approximation (RMSEA) of 0.054 . 


\section{Data analysis}

Data were statistically analyzed using SPSS software version 24.0 (IBM Corp, Armonk, New York, USA). The measured outcomes' mean and standard deviation (SD) are expressed as usual or approximately usual distributions. Enumeration data were presented as frequencies (percentages). Analysis of variance (ANOVA) and individual sample t-test was used to determine the relationship between demographic, clinical characteristics, and work-related fatigue, and the post hoc test was LSD. Pearson's correlation was used to identify the relationship between work-related fatigue, job satisfaction, and nurse-assessed quality of care. Multi-level regression models were used for the mediation analysis. The mean difference double-tail test was also used $(p<0.05)$.

Baron and Kenny [33] described that mediation analysis using a 4-step procedure for cross-sectional data. The prime hypothesis of intermediary analysis is a causal relationship between the independent variable $(X)$ and dependent variable $(Y)$. We used three regression models to test the hypothesis relationships in the theoretical path model among $X$ (work-related fatigue), mediator $(M)$ (job satisfaction), and $Y$ (quality of care). Firstly, the relationship between $X$ (work-related fatigue) and $Y$ (quality of care) was tested. Secondly, where a mediator takes the role of a dependent variable, the association between $\mathrm{X}$ (quality of care) and $\mathrm{M}$ (job satisfaction) was tested. Thirdly, the influence of $\mathrm{M}$ (job satisfaction) on $Y$ (quality of care) would be tested. Finally, $X$ (work-related fatigue) was also added to the model from step 3 , and the effect of $M$ (job satisfaction) was retained. Suppose the effect of $X$ is retained when the effect of $M$ in the model will be assumed as partial mediation [34]. Hayes described that this kind of analysis was performed using PROCESS. Bootstrap was performed with 5,000 iterations to calculate the confidence intervals of the total, direct, and indirect effects. If the limit of confidence did not include zero, effects were regarded as significant.

\section{Results}

Among the 1,299 participants in this present study, 1268 of them (97.6\%) are female. The average age of the participants was 31.42 (SD = 7.45). 902(69.7\%) of the participants had a bachelor's degree and above. Among the demographic variables, age and departments that nurses work in were significantly correlated with work-related fatigue. Nurses aged $26-35$ years old (eta square: $0.013, p<0.001$ ) have a higher level of work-related fatigue. Nurses who worked in the Intensive Care Unit (ICU) had significantly higher work-related fatigue scores (eta square: 0.036, p<0.001) (See Table 1).

T-test results showed that nurses with errors have much higher work-related fatigue than those without errors in Table $2(p<0.01)$. The effect size of each dimension is over 0.2 , and the effect size of mental fatigue accumulation is over 0.4 (footnote in Table 2). More than half of the participants were in moderate $(n=513)$ and severe $(n=206)$ work-related fatigue $(55.4 \%)$ (See Table 3$)$. It suggested that participants without work-related fatigue in level I had high job satisfaction $(2.01 \pm 1.16)$ and high quality of care $(11.49 \pm 4.81)$. Conversely, participants with work-related fatigue in level IV had low job satisfaction (4.02 \pm 1.12$)$ and low quality of care $(21.01 \pm 4.06)$. 
Correlation coefficients between continuous variables were presented in Table 4. The mean perceived quality of care was $16.66 \pm 5.13$ (Low perceived- high perceived: $5-25$ ). Work-related fatigue was associated with quality of care $(r=0.547, P<0.01)$, and job satisfaction was associated with quality of care $(r=0.652, P<0.01)$.

Table 5 showed four steps of mediation analysis. First, we found that work-related fatigue significantly affected the quality of care (total effect, $\beta$ : $0.107,95 \% \mathrm{Cl}$ : $0.098-0.115$ ). Second, a statistically significant correlation was found between $X$ (work-related fatigue) and the mediator (job satisfaction) ( $\beta$ : 0.075, 95\% Cl: 0.067-0.082). The third step showed an association between mediator and quality of care (step 3) was also statistically significant ( $\beta$ : $0.833,95 \% \mathrm{Cl}: 0.778-0.888)$. Fourthly, results indicated that workrelated fatigue had a direct effect after correction for the mediator $(\beta: 0.059,95 \% \mathrm{Cl}: 0.050-0.068)$, that is, job satisfaction (mediator) had a statistically significant effect ( $\beta$ : 0.634 95\%Cl: 0.575-0.694). Following results were obtained for the standardized coefficients in the model: work-related fatigue, $0.303, p<0.001$; dissatisfaction, $0.486, p<0.001$; educational, $0.052, p=0.01$.

The indirect effect of work-related fatigue on the quality of care was statistically significantly associated ( $\beta$ : $0.047,95 \% \mathrm{Cl}: 0.040-0.054)$. Therefore, the magnitude of the indirect effect corresponded to $44 \%$ of the total effect $(\beta: 0.106,95 \% \mathrm{Cl}: 0.097-0.115)$. The indirect effect of work-related fatigue as mediated by job satisfaction corresponded to $\beta$ : 0.047. The direct effect was slightly higher ( $\beta$ : 0.059) (Fig. 1).

\section{Discussion}

In the present study, more than half of the participants were at a high work-related fatigue level. Workrelated fatigue is related to the perceived quality of care. The results verified the assumption that job satisfaction mediated the relationship between quality of care and work-related fatigue. More than half (55.4\%) of nurses were at high levels of work-related fatigue, which was higher than that in physicians [35]. The work-related fatigue score of nursing staff with errors is much higher than those without errors. It is consistent with previous studies investigating the impact of nurses' work-related fatigue on patient safety $[3,4]$. For instance, fatigue nurses were more susceptible to making errors in medication administration and clinical judgment, which were linked to adverse patient outcomes $[14,23,36]$. It indicated that fatigue, emotional exhaustion, and the nature of the work environment among critical care nurses were predictors of overall patient safety. The present study also confirmed that work-related fatigue in nurses contributed to negative impacts such as poor attitude, reduced patience, reduced communication time, and increased error rate $[37,38]$. Like above, the results of Al's study indicated that nurses' workload and fatigue were predictors for overall patient safety [23]. It reminds managers to pay more attention to nurses with high work-related fatigue levels to protect patients' safety.

Furthermore, the mediation analysis showed that half of the effect of work-related fatigue is indirectly mediated by job satisfaction. Job satisfaction refers to how employees feel about their work. Nearly half of the total effect of work-related fatigue directly affects the quality of care in Fig. 1. It was consistent with our hypothesis. The effect of partial mediation might be explained as follows. The scale work-related 
fatigue assesses mental fatigue accumulation and work-related stress that are undesirable from nurses' point of view. As these situations become more frequent, the nurses' job satisfaction decreases. Job satisfaction played a crucial role in improving the quality of care delivery and the nature of the work environment [23]. When nurses have a greater sense of well-being, a positive attitude towards life, and feel supported and respected in their work environment, their care competence increases [39]. Reducing job satisfaction then leads to decreased quality of care. This path is similar to previous research [2]. In brief, job satisfaction played a significant role in nurses' performance. Therefore, promoting job satisfaction in nurses is needed to empower nurses to play a more active role in hospital affairs to enhance the quality of care $[40,41]$. This finding extended our new understanding of the indirect impact of job satisfaction on the quality of care in complex clinical settings.

On the other hand, it is conceivable that high work-related fatigue levels during the typical normal working day may lead to low quality of care. It may be the case that conditions at long work and heavy workload that prevent nurses from implementing professionalism will have a negative effect on work-related fatigue and could directly lead to perceived quality of care. Thus, it is a crucial point to assess workrelated fatigue timely.

These factors, low work-related fatigue levels, and high job satisfaction are essential in improving the quality of care. There have been many different proposals for improving the quality of care. On the one hand, hospital managers should avoid attributing nursing errors solely to individual factors [42]. Hospital administrators have seldom evaluated nurses' physical and mental health in China for purposes of error management [11]. A strategy is needed to establish an environment that would not penalize nurses and help reduce work-related fatigue and promote patient safety [43-45]. The present study found that nurses with proper sleep time and weekly exercise showed lower work-related fatigue scores (Table 1). Thus, moderate exercise and proper sleep may help in reducing work-related fatigue. It meant to give us a clue that hospital managers should maintain reasonable working hours, no more than eight hours [6]. SmithMiller's review indicated that fatigue was significantly linked by decision latitude, job stress, self-rated health, trust in management, and work-family conflict [7]. Additional findings revealed that social support and job stress were positively associated with fatigue. Less social support from colleagues and supervisors is correlated with more fatigue [46]. Therefore, it is hoped that the present study provided a new approach for nursing managers to effectively reduce nursing errors by periodically evaluating workrelated fatigue in nurses and implementing timely and targeted interventions for severe fatigue nurses.

On the other hand, designing intervention programs to enhance job satisfaction is effective for improving QOC. In most cases, due to reduced staffing and increased demand for healthcare, nurses are forced to work extra hours, with limited breaks and heavy workload, as the ratio of patients to nurses is high $[7,47]$. Such factors contribute to an increased level of dissatisfaction among nurses. Extra hours, limited breaks and heavy workload, and a high ratio of patients to nurses are ordinary in China. Meanwhile, Chinese psychological counseling for in-service personnel is still far from perfect $[48,49]$. Therefore, future studies should focus on the impact of interventions related to job satisfaction on QOC. 


\section{Limitations}

The present study had several limitations. First, as collecting the data in the form of a questionnaire, despite our efforts to ensure the quality of the questionnaire, the method may have resulted in standard method variance. Further interventional or longitudinal studies are warranted to enhance our understanding of the issues investigated in this study. Second, the information regarding perceived quality of care was self-reported by nurses, which may have recall bias. Future research should use a mixmethod design to explain the mechanism base on quality of care. Third, job satisfaction was assessed by a one-item questionnaire. Future research should use the reliability and validity scale to measure job satisfaction more comprehensively. Despite the above limitations, the present study provided new insight into the relationship between work-related fatigue, job satisfaction, and quality of care.

\section{Conclusions}

The present study concluded that more than half of the nurses surveyed were moderate to severe workrelated fatigue. Nurses with a high level of work-related fatigue were likely to provide a significantly more inferior quality of care. We confirmed that job satisfaction was a mediator for the relationship between work-related fatigue and quality of care. Therefore, hospitals managers and relevant management departments should consider work-related fatigue and job satisfaction among nurses to improve health services in the future.

\section{Abbreviations}

QOC: Quality of care

OR: Odds ratio

Cl: Confidence interval

\section{Declarations}

\section{Ethical Approval and Consent to participate}

The Medical Ethics Committee of Harbin Medical University approved the study. IRB code is HMUIRB20200004. All participants gave written informed consent.

\section{Consent for publication}

Not applicable.

\section{Availability of supporting data}

The data that support the findings of this study are available from the corresponding author upon reasonable request. 
The authors declare that they have no competing interests.

\section{Funding:}

National Natural Science Foundation of China:71673073

China Scholarship Council: 201808230351

\section{Authors' contributions:}

Study conception and design: YHH

Data collection: All authors

Data analysis and interpretation: XJB, JYN

Drafting of the articles: All authors

Critical revision of the article: All authors

\section{Acknowledgements:}

This research was supported by a National Natural Science Foundation of China $₫$ No. 71673073). We would like to thank all of the participants in this study.

\section{References}

1. Kutney-Lee, A., Wu, E.S., Sloane, D.M., \& Aiken, L.H. (2013). Changes in hospital nurse work environments and nurse job outcomes: an analysis of panel data. International journal of nursing studies, 50,195-201.

2. Liu, Y., \& Aungsuroch, Y. (2018). Factors influencing nurse-assessed quality nursing care: A crosssectional study in hospitals. Journal of advanced nursing, 74,935-945.

3. McHugh, M.D., Stimpfel, A.W. (2012). Nurse reported quality of care: a measure of hospital quality. Res Nurs Health, 35,566 - 75.

4. Fagerström L, Kinnunen M, Saarela J. Nursing workload, patient safety incidents and mortality: an observational study from Finland. BMJ Open. 2018. 8(4): e016367.

5. Holden RJ, Scanlon MC, Patel NR, et al. A human factors framework and study of the effect of nursing workload on patient safety and employee quality of working life. BMJ Qual Saf. 2011. 20(1): $15-24$.

6. Liu X, Zheng J, Liu K, et al. Hospital nursing organizational factors, nursing care left undone, and nurse burnout as predictors of patient safety: A structural equation modeling analysis[J]. Int $\mathrm{J}$ Nurs Stud, 2018,86:82-89. DOI: 10.1016/j.ijnurstu.2018.05.005.

7. Smith-Miller CA, Shaw-Kokot J, Curro B, Jones CB. An integrative review: fatigue among nurses in acute care settings. J Nurs Adm 2014;44:487 - 94. 
8. Ho J, Lee M, Chen R, Chen C, Chang WP, Yeh C, et al. Work-related fatigue among medical personnel in Taiwan. J Formos Med Assoc 2013;112:608.

9. Tang, C., Liu, C., Fang, P., Xiang, Y., \& Min, R. (2019). Work-Related Accumulated Fatigue among Doctors in Tertiary Hospitals: A Cross-Sectional Survey in Six Provinces of China. International journal of environmental research and public health, 16.

10. Saavedra Rionda I, Cortés-García L, de la Villa Moral Jiménez M. The Role of Burnout in the Association between Work-Related Factors and Perceived Errors in Clinical Practice among Spanish Residents. Int J Environ Res Public Health 2021;18.

11. Lu, M., Ruan, H., Xing, W., \& Hu, Y. (2015). Nurse burnout in China: a questionnaire survey on staffing, job satisfaction, and quality of care. Journal of nursing management, 23,440-447.

12. Kang JH, Kim CW, Lee SY. Nurse-Perceived Patient Adverse Events depend on Nursing Workload. Osong Public Health Res Perspect. 2016. 7(1): 56-62.

13. Van Bogaert P, Timmermans O, Weeks SM, van Heusden D, Wouters $K$, Franck E. Nursing unit teams matter: Impact of unit-level nurse practice environment, nurse work characteristics, and burnout on nurse reported job outcomes, and quality of care, and patient adverse events-a cross-sectional survey. Int J Nurs Stud. 2014. 51(8): 1123-34.

14. Scott, L.D., Arslanian-Engoren, C., \& Engoren, M.C. (2014). Association of sleep and fatigue with decision regret among critical care nurses. American journal of critical care : an official publication, American Association of Critical-Care Nurses, 23,13-23.

15. Chang, L.Y., Yu, H.H., \& Chao, Y.C. (2019). The Relationship Between Nursing Workload, Quality of Care, and Nursing Payment in Intensive Care Units. The journal of nursing research : JNR, 27,1-9.

16. Shan HP, Yang XH, Zhan XL, Feng CC, Li YQ, Guo LL, et al. Overwork is a silent killer of Chinese doctors: a review of Karoshi in China 2013-2015. Public Health 2017;147:98-100.

17. Wei, Q., Hao, Y.H., \& Wu, Q.H. (2017). A review of researches on physician overwork and its scale. Chinese Hospital Management.37(12): 56-58. (Original work published in Chinese)

18. Winwood, P.C., Winefield, A.H., Dawson, D., \& Lushington, K. (2005). Development and validation of a scale to measure work-related fatigue and recovery: the Occupational Fatigue Exhaustion/Recovery Scale (OFER). Journal of occupational and environmental medicine, 47,594-606.

19. Shao J, Tang L, Ye Z. Measuring the Nursing Work Environment in Mainland China: Further Development of the Chinese Nursing Work Environment Scale. Nurs Res. 2017. 66(4): 311-322.

20. Alenezi AM, Aboshaiqah $A$, Baker 0 . Work-related stress among nursing staff working in government hospitals and primary health care centres[J]. Int J Nurs Pract, 2018,24(5):e12676.

21. Greaves J, Goodall D, Berry A, Shrestha S, Richardson A, Pearson P. Nursing workloads and activity in critical care: A review of the evidence. Intensive Crit Care Nurs. 2018. 48: 10-20.

22. Zhu L, Zhong S, Tu W, et al. Assessing Spatial Accessibility to Medical Resources at the Community Level in Shenzhen, China. Int J Environ Res Public Health. 2019. 16(2). 
23. Al, M.Q., Sharour, L.A., \& Al, O.O. (2020). Fatigue, burnout, work environment, workload and perceived patient safety culture among critical care nurses. British journal of nursing : BJN, 29,28-34.

24. Aiken LH, Clarke SP, Sloane DM, International Hospital Outcomes Research Consortium. Hospital staffing, organization, and quality of care: cross-national findings. Int J Qual Health Care 2002;14:513.

25. Aiken, L. H., Sermeus, W., Van den Heede K, Sloane, D. M., Busse, R., McKee, M., et al.(2012). Patient safety, satisfaction, and quality of hospital care: cross sectional surveys of nurses and patients in 12 countries in Europe and the United States. BMJ : British medical journal, 344, e1717.

26. Aiken, L.H., Clarke, S.P., Sloane, D.M., Sochalski, J., \& Silber, J.H. (2002). Hospital nurse staffing and patient mortality, nurse burnout, and job dissatisfaction. JAMA, 288,1987-1993.

27. Liu, Y., Aungsuroch, Y., \& Yunibhand, J. (2016). Job satisfaction in nursing: a concept analysis study. International nursing review, 63,84-91.

28. Kwak C, Chung BY, Xu Y, Eun-Jung C. Relationship of job satisfaction with perceived organizational support and quality of care among South Korean nurses: a questionnaire survey. Int J Nurs Stud 2010;47:1292-8.

29. Van Bogaert P, Clarke S, Vermeyen K, Meulemans H, Van de Heyning P. Practice environments and their associations with nurse-reported outcomes in Belgian hospitals: development and preliminary validation of a Dutch adaptation of the Revised Nursing Work Index. Int J Nurs Stud 2009;46:54-64.

30. Loerbroks, A., Weigl, M., Li, J., \& Angerer, P. (2016). Effort-reward imbalance and perceived quality of patient care: a cross-sectional study among physicians in Germany. BMC public health, 16,342.

31. Wei, Q., Hao, Y.H., \& Liang, L.L. (2018). Compilation of Doctor's Overwork Scale and Analysis of Reliability and Validity. Chinese Hospital Management.38: 50-52. (Original work published in Chinese)

32. https://www.jniosh.johas.go.jp/icpro/jicoshold/english/topics/AccumulatedFatigueCheckList/Accumulated Fatigue CheckList.html .

33. Baron, R.M., \& Kenny, D.A. (1986). The moderator-mediator variable distinction in social psychological research: conceptual, strategic, and statistical considerations. Journal of personality and social psychology, 51,1173-1182.

34. Koch, P., Zilezinski, M., Schulte, K., Strametz, R., Nienhaus, A., \& Raspe, M. (2020). How Perceived Quality of Care and Job Satisfaction Are Associated with Intention to Leave the Profession in Young Nurses and Physicians. International journal of environmental research and public health, 17.

35. Yi, M., Hao, H.Y., \& Liang, L. (2018).Analysis of overwork Status and Influencing Factors of Clinicians in North west Third-Class A Hospital of Heilongjiang Province. Chinese Hospital,22(12): 29-32. (Original work published in Chinese)

36. Jin, H., Chen, H., Munechika, M., Sano, M., \& Kajihara, C. (2018). The effect of workload on nurses' non-observance errors in medication administration processes: A cross-sectional study. International journal of nursing practice, 24,e12679. 
37. AMM, M., DGD, C., Riboldi, C.O., Mergen, T., ADS, B., \& GMSS, M. (2017). Association between workload of the nursing staff and patient safety outcomes. Revista da Escola de Enfermagem da US $P, 51, \mathrm{e} 03255$.

38. Carlesi, K.C., Padilha, K.G., Toffoletto, M.C., Henriquez-Roldán, C., \& Juan, M.A. (2017). Patient Safety Incidents and Nursing Workload. Revista latino-americana de enfermagem, 25,e2841.

39. Chung HC, Chen YC, Chang SC, Hsu WL, Hsieh TC. Development and Validation of Nurses' Well-Being and Caring Nurse-Patient Interaction Model: A Psychometric Study. Int J Environ Res Public Health $2021 ; 18$.

40. Mrayyan, M.T. (2006). Jordanian nurses' job satisfaction, patients' satisfaction and quality of nursing care. International nursing review, 53,224-230.

41. Al, S.S.D., Labrague, L.J., Miner, R.A., Karkada, S., Albashayreh, A., Al, M.F., et al. (2020). Nursing Work Environment, Turnover Intention, Job Burnout, and Quality of Care: The Moderating Role of Job Satisfaction. Journal of nursing scholarship : an official publication of Sigma Theta Tau International Honor Society of Nursing, 52,95-104.

42. Zhang X, Li Q, Guo Y, Lee SY. 2019. From organisational support to second victim-related distress: Role of patient safety culture. J Nurs Manag. 27(8): 1818-1825.

43. McHugh MD, Rochman MF, Sloane DM, et al. Better Nurse Staffing and Nurse Work Environments Associated With Increased Survival of In-Hospital Cardiac Arrest Patients. Med Care. 2016. 54(1): 74-80.

44. Roberts RK, Grubb PL. The consequences of nursing stress and need for integrated solutions. Rehabil Nurs. 2014. 39(2): 62 - 9.

45. Shirey MR, McDaniel AM, Ebright PR, Fisher ML, Doebbeling BN. Understanding nurse manager stress and work complexity: factors that make a difference. J Nurs Adm. 2010. 40(2): 82-91.

46. Lo SF, Spurgeon P. Working hours of surgical residence: perspective of a group of surgeons in a regional hospital in Hong Kong[J]. Asian J Surg, 2007,30(1):60-66. DOI: 10.1016/S10159584(09)60130-5.

47. Cimiotti JP, Aiken LH, Sloane DM, Wu ES. Nurse staffing, burnout, and health care-associated infection. Am J Infect Control 2012;40:486 - 90.

48. Lou NM, Montreuil T, Feldman LS, et al. Nurses' and Physicians' Distress, Burnout, and Coping Strategies During COVID-19: Stress and Impact on Perceived Performance and Intentions to Quit. J Contin Educ Health Prof. 2021.

49. Riley R, Kokab F, Buszewicz M, et al. Protective factors and sources of support in the workplace as experienced by UK foundation and junior doctors: a qualitative study. BMJ Open. 2021. 11(6): e045588.

\section{Tables}

Table 1. Comparative characteristics of surveyed nurses, by work-related fatigue $(N=1299)$ 


\begin{tabular}{|c|c|c|c|}
\hline Variables & Nu.(PER\%) & Score $(x \pm s)$ & $T / F(P)$ \\
\hline \multicolumn{4}{|l|}{ Gender } \\
\hline Male & $31(2.4)$ & $64.16 \pm 28.67$ & \\
\hline Female & 1268(97.6) & $62.96 \pm 26.38$ & $0.441 / 0.659$ \\
\hline \multicolumn{4}{|l|}{ Marital status } \\
\hline Never married & $442(34.0)$ & $62.34 \pm 27.03$ & \\
\hline Married/living together & $835(64.3)$ & $63.54 \pm 25.95$ & \\
\hline Others & $22(1.7)$ & $55.16 \pm 29.23$ & $1.104 / 0.332$ \\
\hline \multicolumn{4}{|l|}{ Age(years) } \\
\hline$<25$ & 272(20.9) & $57.64 \pm 27.45$ & \\
\hline $26-35$ & $708(54.5)$ & $65.41 \pm 25.58$ & \\
\hline$>35$ & $319(24.6)$ & $62.20 \pm 26.57$ & $8.823 / * \star \star$ \\
\hline \multicolumn{4}{|l|}{ Educational level } \\
\hline Vocational Technical school & 74(5.7) & $66.04 \pm 27.16$ & \\
\hline College degree & $319(24.6)$ & $60.10 \pm 28.06$ & \\
\hline Bachelor's degree and above & $902(69.7)$ & $63.91 \pm 25.57$ & $2.395 / 0.092$ \\
\hline \multicolumn{4}{|l|}{ Department } \\
\hline 1 Internal medicine & $456(35.1)$ & $66.19 \pm 25.20$ & \\
\hline 2 Surgery department & 482(37.1) & $60.09 \pm 26.41$ & \\
\hline 3 Obstetrics and gynecology & 107(8.2) & $54.42 \pm 28.15$ & \\
\hline 4 Pediatric & $70(5.4)$ & $66.12 \pm 26.95$ & \\
\hline 5 Emergency & $26(2.0)$ & $73.46 \pm 21.21$ & \\
\hline $6 \mathrm{ICU}$ & $38(2.9)$ & $80.78 \pm 19.11$ & \\
\hline 7 Others & $120(9.2)$ & $60.42 \pm 19.10$ & 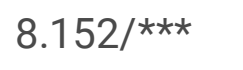 \\
\hline \multicolumn{4}{|l|}{ Sleep hour per day } \\
\hline$<6 h$ & $126(9.7)$ & $78.47 \pm 23.75$ & \\
\hline $6 h-8 h$ & 1148(88.4) & $61.66 \pm 26.02$ & \\
\hline$>8 \mathrm{~h}$ & $25(1.9)$ & $46.21 \pm 26.62$ & 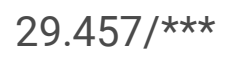 \\
\hline Work hour per day & & & \\
\hline
\end{tabular}




\begin{tabular}{|llll|}
\hline$<=8 \mathrm{~h}$ & $880(67.7)$ & $58.17 \pm 26.47$ & \\
\hline$>8 \mathrm{~h}$ & $419(32.3)$ & $73.13 \pm 23.15$ & $-10.111 /$ \\
\hline Exercise per week & & & \\
\hline Yes & $826(63.6)$ & $58.22 \pm 26.33$ & \\
\hline No & $457(35.2)$ & $71.48 \pm 24.46$ & $8.358 / * \star \star$ \\
\hline
\end{tabular}

Note. ${ }^{* \star *} P<0.001$ in LSD of the post hoc test: Age $<25$ compare $26-35 p<0.001$;

$<25$ compare $>35 p<0.05 ; 26-35$ compare $>35 p=0.07$. Sleep $<6$ compare $6-8 \mathrm{~h} p<0.01 ;<6 \mathrm{~h}$ compare $>8 \mathrm{~h}$ $p<0.001$; $<6$ compare 6-8h $p<0.001$; Department: 6 compare $1 p<0.001$ 6compare $2 p<0.001 ; 6$ compare 3 $p<0.001 ; 6$ compare $4 p<0.01 ; 6$ compare $5 p=0.268 ; 6$ compare $7 p<0.001$.

Table 2 Dimensions of work-related fatigue in Nurses with perceived nursing Errors

\begin{tabular}{|lllll|}
\hline Dimensions & $\begin{array}{l}\text { Items } \\
(\text { Score })\end{array}$ & $\begin{array}{l}\text { Nurses } \\
\text { With Errors(82) }\end{array}$ & $\begin{array}{l}\text { Nurses without } \\
\text { Errors(1217) }\end{array}$ & T/P \\
\hline 1 Working hours & $4(16)$ & $8.56 \pm 3.81$ & $6.65 \pm 4.06$ & $4.134^{\star \star \star}$ \\
\hline 2 Work-related stress & $6(24)$ & $15.00 \pm 5.42$ & $12.54 \pm 6.04$ & $3.596^{\star \star \star}$ \\
\hline 3 General feeling of fatigue & $10(40)$ & $32.63 \pm 8.63$ & $26.42 \pm 10.56$ & $6.215^{\star \star \star}$ \\
\hline 4 Physical fatigue accumulation & $5(20)$ & $12.57 \pm 4.63$ & $8.66 \pm 5.39$ & $7.323^{\star \star \star}$ \\
\hline 5 Mental fatigue accumulation & $5(20)$ & $12.28 \pm 5.08$ & $7.51 \pm 5.51$ & $7.625^{\star \star \star}$ \\
\hline Total & $30(120)$ & $81.05 \pm 22.28$ & $61.78 \pm 26.20$ & $7.491^{\star \star \star}$ \\
\hline
\end{tabular}

Note. ${ }^{* \star *} P<0.001$ in t-test Effect size: $1,0.236,2,0.210,3,0.306,4,0.362,5,0.410$, Total 0.368

Table 3 Job satisfaction and quality of care at different levels of work-related fatigue

\begin{tabular}{|llll|}
\hline Level of work-related fatigue & Job satisfaction(1-5) & Quality of Care(5-25) & Cases (\%) \\
\hline I (0-30) & $2.01 \pm 1.16$ & $11.49 \pm 4.81$ & $1211(9.3)$ \\
\hline II (31-60) & $2.71 \pm 1.09$ & $14.91 \pm 4.54$ & $459(35.3)$ \\
\hline III (61-90) & $3.40 \pm 1.10$ & $17.71 \pm 4.30$ & $513(39.5)$ \\
\hline IV (91-120) & $4.02 \pm 1.12$ & $21.01 \pm 4.06$ & $206(15.9)$ \\
\hline Total & $3.12 \pm 1.25$ & $16.66 \pm 5.13$ & $1299(100)$ \\
\hline
\end{tabular}

Note. I, 0-30, none; II, 31-60, mild work-related fatigue; III, 61-90, moderate work-related fatigue; IV, 91120, severe work-related fatigue. In Job satisfaction, 5 means dissatisfaction. In perceived Quality of 
Care, 25 means inferior quality of care.

Table 4 Correlation analyses of the nurses' work-related fatigue, job satisfaction and nurse-assessed quality of care

\begin{tabular}{|llllll|}
\hline Variable & Mean & SD & Work-related fatigue & Job satisfaction & QOC \\
\hline Work-related fatigue & 62.993 & 26.380 & 1 & & \\
\hline Job satisfaction & 3.120 & 1.246 & $0.501^{\star \star}$ & 1 & \\
\hline QOC & 16.656 & 5.129 & $0.547^{\star \star}$ & $0.652^{\star \star}$ & 1 \\
\hline
\end{tabular}

Note. ${ }^{*} P<0.01$ in Pearson's correlation. Q0C: Quality of care

Table 5 Regression model of the mediation analysis

\begin{tabular}{|c|c|c|c|c|c|c|c|c|}
\hline & \multicolumn{2}{|c|}{ Quality of care } & \multicolumn{2}{|c|}{ Job satisfaction } & \multicolumn{2}{|c|}{ Quality of care } & \multicolumn{2}{|c|}{ Quality of care } \\
\hline & \multicolumn{2}{|l|}{ Step 1} & \multicolumn{2}{|l|}{ Step 2} & \multicolumn{2}{|c|}{ Step 3} & \multicolumn{2}{|l|}{ Step 4} \\
\hline & beta & $95 \% \mathrm{Cl}$ & beta & $95 \% \mathrm{Cl}$ & beta & $95 \% \mathrm{Cl}$ & beta & $95 \% \mathrm{Cl}$ \\
\hline Constant & $\begin{array}{l}9.317 \\
\star \star\end{array}$ & $\begin{array}{l}5.962- \\
12.671^{\star \star}\end{array}$ & $\begin{array}{l}6.292 \\
\star \star\end{array}$ & $\begin{array}{l}3.633- \\
8.950\end{array}$ & $\begin{array}{l}6.891 \\
\star \star\end{array}$ & $\begin{array}{l}3.790- \\
9.991\end{array}$ & $\begin{array}{l}5.432 \\
\star \star\end{array}$ & $\begin{array}{l}2.508- \\
8.356\end{array}$ \\
\hline Overwork & $\begin{array}{l}0.107 \\
\star *\end{array}$ & $\begin{array}{l}0.098-0.115 \\
\star *\end{array}$ & $\begin{array}{l}0.075 \\
\star *\end{array}$ & $\begin{array}{l}0.067- \\
0.082\end{array}$ & - & - & $\begin{array}{l}0.059 \\
\star \star\end{array}$ & $\begin{array}{l}0.050- \\
0.068\end{array}$ \\
\hline $\begin{array}{l}\text { Job } \\
\text { satisfaction }\end{array}$ & - & - & NA & NA & $\begin{array}{l}0.833 \\
\star \star\end{array}$ & $\begin{array}{l}0.778- \\
0.888\end{array}$ & $\begin{array}{l}0.634 \\
\star \star\end{array}$ & $\begin{array}{l}0.575- \\
0.694\end{array}$ \\
\hline R2 & 30.0 & & 25.3 & & 41.1 & & 47.7 & \\
\hline
\end{tabular}

Note. Adjusted for age $₫$ gender, educational level, departments $\rrbracket^{\star \star} p<0.01$

\section{Figures}




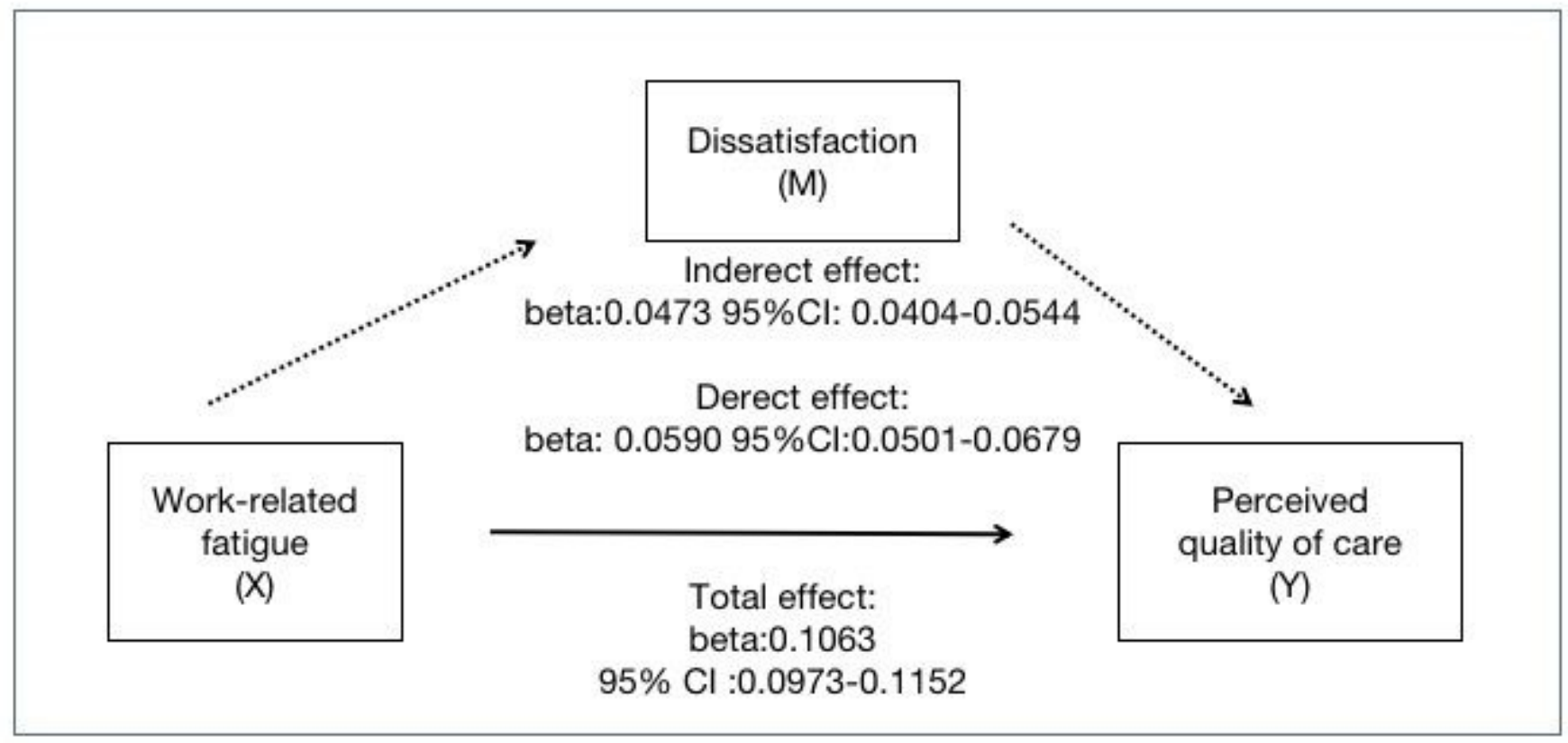

Figure 1

Results of the mediation with portrayal of the calculated effects 